\title{
ENTRE A TRINCHEIRA DE COMBATE E A CAIXA REGISTRADORA
}

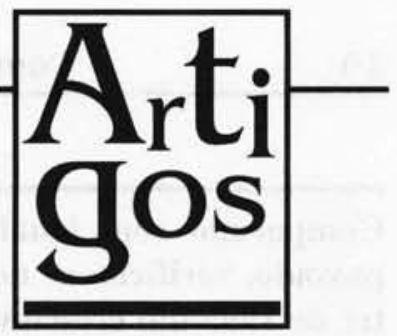

nacionais

\section{O direito democrático à informação, ao ser superado pelos interesses comerciais das empresas de comunicação, coloca para a sociedade civil novas questões de ordem ética, jurídica e profissional}

Em 1990, eu era editor de Política do jornal O Estado de S. Paulo e me lembro muito bem das reuniões de que participava com o pessoal do Departamento de Pesquisa para tentar evitar uma tendência que parecia irreversível. À época, O Estado já perdia, nos dias úteis da semana, mas ainda vendia mais do que seu maior concorrente, a Folha de S. Paulo, aos domingos. Em abril de 1990, O Estado tirava algo próximo dos 450 mil exemplares aos domingos e a Folha tinha uma tiragem bastante semelhante.

Em 30 de abril, os caminhões de distribuição de $\mathbf{O}$ Estado levaram às bancas e aos assinantes do jornal 599 mil exemplares, enquanto os da Folha distribuíram um milhão e 557 mil. Grosso modo, é possível dizer que o tradicional diário da família Mesquita teve um significativo aumento de $34 \%$ em sua tiragem nos últimos cinco anos. Mas, ainda assim, perdeu feio em vendas para o concorrente, que conseguiu o feito de multiplicar por três e meio seu mercado consumidor.

Um aumento de mercado de $350 \%$ em cinco anos - e mesmo o de $34 \%$ - é um feito espetacular em matéria de escala. Se alguns negócios conseguiram repetir esse feito, certamente não terão sido muitos, pelo menos aqui no Brasil. Trata-se de algo que até Bill Gates, da Microsoft, certamente comemoraria.

Antoninho Marmo Trevisan, um dos maiores consultores de empresas e de negócios do Brasil, só se lembrou de um setor industrial que conheceu uma mudança de escala tão significativa, neste mesmo período. Refiro-me à indústria automobilística, que fabricava 700 mil veículos em 1993 e fechou 1995 com 2 milhões, ou seja, teve um desempenho de crescimento de mercado proporcionalmente semelhante ao do universo de leitores da Folha de S. Paulo.

É claro que são valores bastante diferentes. Mas eu gostaria de advertir que o boom da comunicação continua a pleno vapor agora. É possível dizer que ainda estamos no olho do furacão. Basta lembrar os dados divulgados pela Intermeios na publicação especializada Meio e Mensagem sobre mercado publicitário, em janeiro e fevereiro.

\section{O AUTOR}

José Nêumanne

Jornalista e articulista do jornal O Estado de São Paulo.

1. Texto apresentado na mesa redonda sobre A ética do judiciário e a ética da imprensa, em maio de 1995, no auditório do Tribunal de Justiça do Estado do Rio de Janeiro. 
Comparado com igual período no ano passado, verificou-se no primeiro bimestre de 1995 um crescimento de $\mathbf{5 9 , 7 \%}$ do mercado publicitário, sendo que a publicidade nos jornais cresceu $\mathbf{7 2 , 3 \%}$ e nas revistas, $80,3 \%$. Trevisan dá um palpite muito sensato: a competição entre as empresas aquece o mercado publicitário e a informação é um produto que está sendo cada vez mais valorizado.

Houve, nos últimos cinco anos, uma mudança espetacular de escala no negócio de imprensa no Brasil. Toninho Rosa, da Dainet Multimídia e Comunicações, proporcionou-me, muito generosamente, os números que identificam exatamente o momento do salto. Ele ocorreu entre julho e agosto do ano passado. Naquela ocasião, a Folha praticamente dobrou sua tiragem, passando de 650 mil para mais de um milhão e 100 mil e O Estado cresceu dos 450 mil para 510 mil.

Ou seja, enquanto $\mathbf{O}$ Estado teve sua tiragem aumentada em 13\%, a Folha conheceu o mesmo crescimento no nível espantoso de $90 \%$ em um mês. Se se considerar que os dois "jornalões" paulistas foram beneficiados pelo Plano Real, que começou a vigir à época, é o caso de se imaginar que o crescimento espetacular do segundo, já então o maior jornal do País, se deveu a sua declarada adesão ao marketing, com a publicação dominical do Atlas Geográfico do New York Times.

\section{MARKETING OU JORNALISMO}

A meu ver, a mudança de escala no negócio da imprensa está provocando uma al- teração ainda mais importante: uma modificação da própria natureza social dos meios de comunicação, neste fim de milênio. A velha imprensa, representada pela Galáxia de Gutenberg e definida pelo Prêmio Nobel de Literatura Albert Camus, ele mesmo um brilhante jornalista, como uma "fraternidade de combate", não existe mais ou, no mínimo, está preparando sua retirada da cena ${ }^{2}$.

Em seu lugar, surge um complexo industrial e comercial, um segmento econômico que negocia, e muitas vezes fabrica, uma das mais valiosas commodities de todos os tempos: a informação.

Com um pouco de temor de cair na simplificação, mas com a intenção de ganhar em clareza, proponho que a atividade política e social dos meios na trincheira de combate seja aqui definida como comunicação e este novo negócio - a grande indústria que produz para a enorme feira livre da curiosidade popular - receba a denominação que mais comumente lhe é dada: mídia, aportuguesamento da palavra latina, já antes adotada no inglês.

A atividade combativa e política tem limites muito claramente definidos, até mesmo geográficos e, sobretudo, lingüísti$\cos$. O grande negócio, não. Ele funciona na "aldeia global", imaginada palo canadense Marshall McLuhan ${ }^{3}$. Como escreveu João Roberto Marinho, diretor do jornal O Globo, em artigo publicado na Folha de $\mathbf{S}$. Paulo, "o mercado da mídia vem sendo um dos mais afetados pelo avassalador processo de globalização da economia". Quero destacar o fato de que a palavra de João Roberto, autorizada em si mesma, ganha mais valor

\footnotetext{
2. Ver também sobre o assunto o artigo de COSTA, Luciano Martins. Um brinde pela educação. Comunicação \& Educação. São Paulo: CCA/ECA-USP; Moderna, nº.3, mai./ago. 1995, p.43-46.

3. McLUHAN, Marshall. Guerra e paz na aldeia global. Rio de Janeiro: Record, 1971.
} 


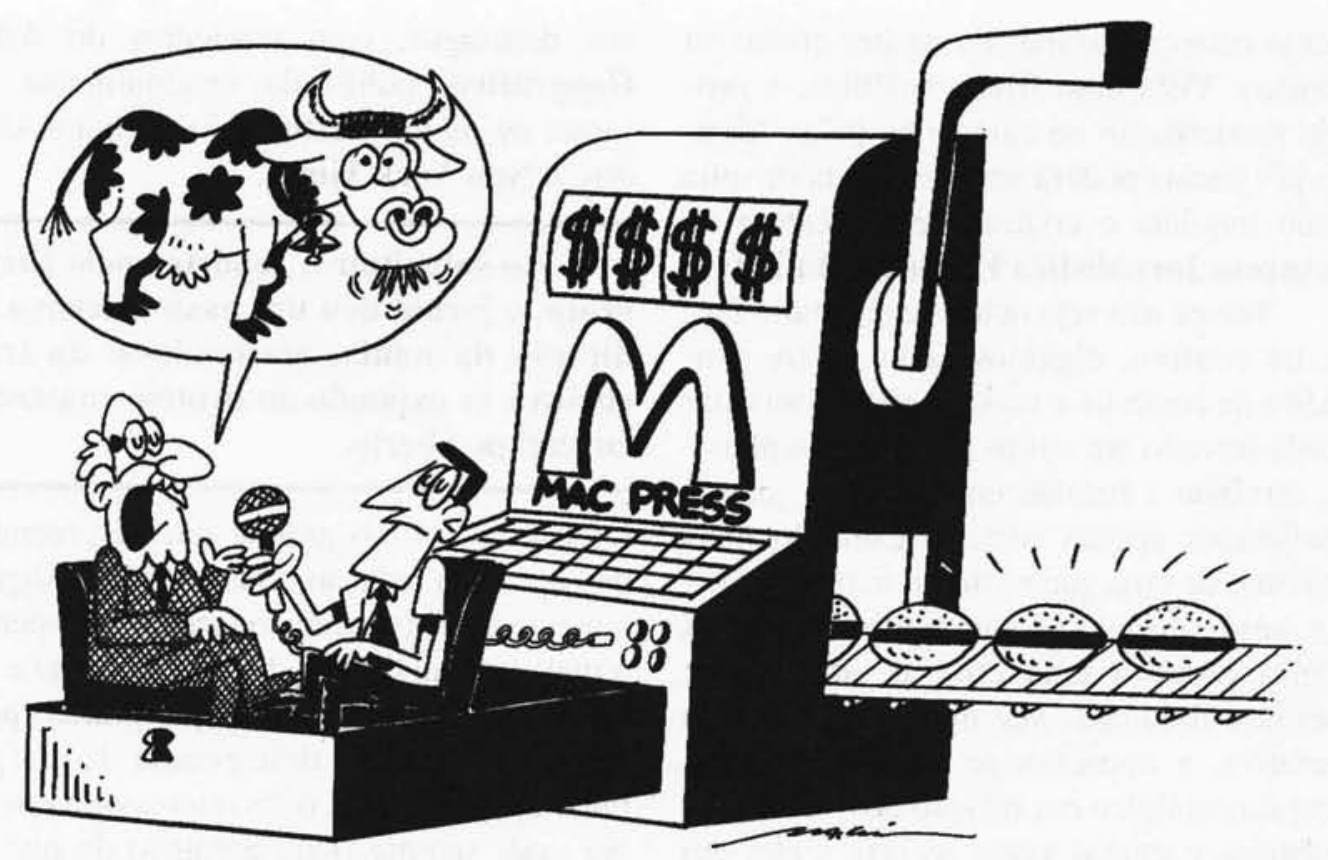

por ter sido reproduzida nos dois maiores jornais diários do País, justamente, e não por acaso, os dois que entenderam mais rapidamente a necessidade de mudança da natureza de seu próprio negócio.

Com o mesmo temor de simplicar e a mesma intenção de facilitar a compreensão de todos, talvez fique mais claro voltar aos dois jornais de São Paulo, adotando-os como modelos dos dois tipos de atividade. O Estado de S. Paulo é um excelente exemplo de instrumento da "fraternidade de combate" do maquis ${ }^{4}$ Camus, desde suas origens mais remotas. O jornal foi fundado para combater a escravatura e pregar o ideal republicano, nos estertores do Segundo Império.

Tem reagido com olímpica indiferença ao fenômeno mais característico da imprensa nestes meados do decênio final do século: a substituição da notícia pela pres- tação de serviços e pelo marketing como carro-chefe de vendas das publicações periódicas impressas. $\mathrm{O}$ investimento da empresa proprietária do tradicional matutino paulista em meios eletrônicos alternativos de comunicação, tais como os veículos on real time, são a exceção que não pode desmentir esta regra.

A Folha de S. Paulo, ao contrário, não tem a mesma tradição histórica, acumulada por seu principal concorrente em São Paulo, de assumir posições de tiro na imprensa de trincheira. Apesar de ter sido notória sua liderança em pelo menos um momento político importante da História recente do Brasil, a campanha pelas eleições diretas para Presidência da República, em 1983 e 1984, esta não tem sido sua característica mais forte.

O jornal de seu Frias é muito mais comprometido com o investimento forte em serviços e em marketing do que propria-

4. Termo proveniente do francês e que se refere a lugar de difícil acesso onde se reuniam os membros da resistência clandestina à ocupação alemã, por ocasião da II Guerra Mundial. (N.E.) 
mente com campanhas de caráter cívico ou político. Vista com frieza analítica, a própria participação na campanha pelas "diretas já" jamais poderá ser dissociada de uma visão inquieta e criativa de marketing da Empresa Jornalística Folha da Manhã.

Talvez não seja ocioso constatar o fato de tal conflito, digamos assim, entre trincheira de combate e caixa registradora estar sendo travado em outras paragens do planeta, servindo a batalha entre os dois jornais paulistanos apenas como o exemplo mais próximo de uma guerra muito mais ampla.

Da mesma forma, não temo afirmar que tal guerra provoca uma crise de identidade: mesmo sendo cada vez mais uma indústria lucrativa, a imprensa de Johannes Gutenberg é nostálgica em relação aos velhos românticos e muitas vezes recorre a eles em defesa de seus interesses como negócio.

\section{DISPUTAS COMERCIAIS}

Assim sendo, incorre em equívoco sério quem imaginar que a mídia pode ser regida pelos mesmos conceitos éticos e pelas mesmas normas jurídicas que vigiavam a atividade em seus velhos tempos de combate político. É preciso pensar cada vez menos em direito privilegiado político e institucional, e cada vez mais em direito comercial comum e em impasses políticos como a distinção entre o público e o privado.

Retomemos justamente do salto detectado por Toninho Rosa na passagem de julho para agosto do ano passado. O que aconteceu de extraordinário naquela ocasião para justificar a multiplicação por dois da tiragem da Folha de S. Paulo em apenas um mês? Já então o jornal que mais circulava no País, a Folha, resolveu assumir publicamente sua opção pelo primado do marketing e dos serviços sobre a notícia, ao circular, aos domingos, com fascículos do Atlas Geográfico, publicado originalmente no jornal de maior prestígio dos Estados Unidos, o New York Times.

Ao substituir o repórter pelo cartógrafo, o jornal deu um passo decisivo na direção da mídia, afastando-se da trincheira e se expondo ao tiroteio comercial em campo aberto.

O sucesso foi tão grande que surpreendeu não apenas a redação, mas também o departamento de circulação do jornal. De repente, o maior jornal do País ficou sem papel e teve de substituir todo o parque gráfico para atender à demanda desesperada de um público desconhecido, mais interessado em saber onde sempre ficou Sarajevo do que no relato circunstanciado das atividades do Congresso Nacional, na véspera.

Todo o mercado se manteve em expectativa em relação ao mistério que se gerou: completado o Atlas, o que o jornal faria para segurar os novos leitores, ávidos por geografia e desinteressados do noticiário comum? Ainda é cedo para responder a esse enigma, permanentemente em aberto. Mas já se sabe que o interesse do novo leitor, que dobrou a circulação já alta do jornal, manteve-se graças a uma engenhosa mistura de marketing, serviços e notícias de impacto.

\section{RECEITA INFALÍVEL}

Outros periódicos lhe seguiram o passo: O Globo, jornal de maior circulação no Rio e segundo maior do País, está vendendo, em suas edições dominicais, um Atlas Histórico; e a segunda maior revista do Brasil, a IstoÉ, uma enciclopédia genérica e resumida. O Estadão mantém-se fiel a suas tradi- 
ções de combate, mas outro diário da mesma empresa, o Jornal da Tarde, entrou na onda.

A primeira página da Folha de domingo é um exemplo perfeito dessa receita: nela misturam-se produtos de marketing, serviços para o leitor e notícias, e de preferência revelações escabrosas, escândalos e denúncias, capazes de satisfazer a enorme curiosidade do público na sociedade de consumo de massa desta fase pós-Terceira Revolução Industrial. Não há nesta mera constatação nenhum juízo de valor.

No entanto, não há como escapar da observação de uma evidência: o jornalismo que tem sobrado no meio das jogadas dos marqueteiros e do volume de serviços impressos em letra de forma é muito ligeiro, considerando-se todos os sentidos possíveis desta palavra.

O já citado Albert Camus detectava esse problema em oito de setembro de 1944 , ao registrar no artigo apropriadamente intitulado $O$ Jornalismo Crítico, publicado em Combat ${ }^{5}$ : "querem informar rápido em vez de informar bem. A verdade não ganha nada com isso".

Não há como escapar desta evidência cruel. Já se falou em hard journalism e em new journalism 6 .

Esta é a hora de prestar atenção na vite presse de Camus, o fast journalism, estilo McDonald's, o jornalismo ligeiro ou, ainda, light, como prefere o professor Carlos Alberto di Franco. Nesse tipo de imprensa, vale mais o impacto da versão do que a verdade dos fatos realmente ocorridos.

Sua manifestação mais comum se passa nas colunas, que proliferam cada vez mais nos jornais brasileiros de uns tempos para cá, mas também já contaminou as páginas dos noticiários político, econômico, policial e esportivo. Nele denuncia-se, não se investiga.

\section{CONSUMO INDIGESTO}

O jornalismo ligeiro, às vezes, é tão ligeiro que se esquece de uma das lições fundamentais do velho e bom jornalismo dos fatos, a necessidade de ouvir os dois lados. Uma vez, um colega colunista deu-me talvez a melhor definição do fast journalism, com uma constatação cínica: uma notícia errada pode significar duas notas de coluna, a primeira contendo a mentira; a segunda, o desmentido. Se ele tivesse tido o trabalho de conferir antes, não teria nota nenhuma. Como não conferiu, conseguiu duas. Qual das duas é verdadeira? O leitor nunca saberá.

Um dia destes, a Folha de S. Paulo deu um exemplo prático de como pode funcionar a vite presse de Camus. Um ex-funcionário da Força Sindical acusou o presidente daquela central, Luís Antônio de Medeiros, de manipular de forma ilícita recursos em contas no exterior. Medeiros foi ouvido pelo jornal e na mesma edição desmentiu tudo. O leitor apressado pode pensar que o jornal cumpriu seu dever elementar de ouvir os dois lados. Certo? Errado! O leitor ficou sem saber se a denúncia era correta, ou não. A obrigação de investigar quem estava com razão não é do leitor, mas do jornal.

Mesmo sem ter aderido ainda ao primado do marketing e dos serviços sobre o noticiário, $\mathbf{O}$ Estado de $\mathbf{S}$. Paulo também às vezes exibe seus exemplos claros de jornalismo ligeiro. Já dei um desses exemplos

5. CAMUS, Albert.Combat clandestin.(Combate clandestino) In: Actuelles chroniques 1944-1948. (Crônicas atuais 1944 1948) 24. ed. Paris:Gallimard, 1950.

6. Ver síntese sobre o assunto na nota de rodapé (n.5) da revista Comunicação \& Educação, ano I, n.3, mai./ago. 1995 , p.43. 
em um artigo que escrevi para a revista Imprensa de fevereiro passado.

$\mathrm{Na}$ legenda de um conjunto de fotos do Ministro da Administração, Bresser Pereira, o tradicional jornal deu uma verdadeira aula da soma rápida de preconceitos e meias-verdades compondo uma versão bastante distanciada da verdade. $\mathrm{O}$ fotógrafo flagrou o Ministro fazendo exercícios à beira da piscina da Academia de Tênis, em Brasília. O redator lembrou ao leitor que naquele mesmo local, a ex-Ministra Zélia Cardoso de Mello havia tramado o confisco da poupança dos brasileiros. A câmara fotográfica capturou o momento no qual o Ministro tomava banho em uma cachoeira artificial. O teclado compôs um texto relacionando o banho com a Casa da Dinda, residência do ex-presidente Collor. Nunca Josef Goebbels poderia imaginar conseguir nestes tristes trópicos discípulo tão fiel. De fato, esse tipo de manipulação de meiasverdades, própria das cargas de imprensa ligeira, chega até a aproximar a atividade jornalística da ficção.

Gaudêncio Torquato, professor de marketing político na Escola de Comunicações e Artes da USP, já observou que "o excesso de informação não significa, necessariamente, acesso à verdade, pois a realidade está sendo banalizada e o grande público consome uma espécie de ficção disfarçada. $\mathrm{Na}$ verdade, existem duas realidades: a das ruas e a da mídia".

Essa dualidade, de certa forma, aproxima o jornalista de uma espécie de ficção semireal, atividade na qual realiza um pouco seus sonhos de escritor. Qual jornalista não é um escritor frustrado? Só que este é o caminho inverso do new journalism de Tom Wolfe ${ }^{7}$, aquele que escreveu a definição mais cruel e mais exata do fast journalism, quando era apenas um embrião: "só existem duas maneiras de fazer carreira em jornalismo. Construindo uma boa reputação ou destruindo uma".

E me faz lembrar uma frase anotada de um clássico do estudo da proximidade e da distância entre as duas atividades. Em Jornalismo e Literatura, o mineiro Antônio Olinto, que durante 40 anos assinou uma coluna de crítica literária, Porta de Livraria, no jornal O Globo, escreveu: "toda reportagem é, de início, um conto que o jornalista escreve baseado em coisas presentes, atuais".

$\mathrm{O}$ fato é que Gaudêncio Torquato tem razão: vender excesso de informação não significa quase nunca permitir o acesso democrático do grande público à verdade. Às vezes, significa exatamente o contrário. Como lembra Richard Sennett, em O Declínio do Homem Público ${ }^{8}$, "os meios de comunicação aumentaram amplamente o estoque de conhecimentos que os grupos sociais tinham uns dos outros, mas tornaram o contato efetivo desnecessário". Ou seja, em sua análise sobre As Tiranias da Intimidade: "a mídia elevou infinitamente o conhecimento que as pessoas tinham daquilo que transpira na sociedade e inibiu infinitamente a capacidade de as pessoas converterem esse conhecimento em ação política".

A verdade é que a nova mídia, a comunicação vista como um negócio, qual seja a comercialização de produtos de marketing, serviços e do noticiário ligeiro no gatilho, ou melhor, o primado da caixa registradora sobre a trincheira de combate, está a exigir uma nova conceituação ética. Pois a ética nunca é dispensável em uma atividade como a jornalística. 
Tomo emprestadas as palavras de um mestre do melhor jornalismo, Luís Garcia, editor de opinião de $\mathbf{O}$ Globo, ao lembrar que a ética não pede menos notícias, mas melhores notícias, apuradas com rigor e dignidade.

Da mesma forma, se a mídia é um comércio, a atividade deve ser regida cada vez mais por uma ética comercial e por um direito comercial comum, não mais por um direito político privilegiado. Se a Lei de Imprensa já era um exagero nos tempos da "fraternidade de combate", nesta época dos grandes impérios empresariais da comunicação de massa passou a ser um absurdo.

\section{ÉTICA E DIREITO COMERCIAL}

Ao sair da trincheira e entrar no mercado, a imprensa não pode mais usar os valores românticos do passado como biombos para seus interesses cada vez mais pecuniários, cada vez menos ideológicos. É racional combater a demonização do lucro, mas cínico elevar o tilintar da máquina registradora à condição de "hino à liberdade de expressão". A questão é: um negócio, cuja escala deixa a casa da centena do milhar e passa para a do milhão (caso da Folha, da Veja e de $\mathbf{O}$ Globo), ainda pode se beneficiar do direito de usar os velhos ideais românticos do passado?

Um episódio recente pode ser bastante esclarecedor desta minha opinião, que, reconheço, é muito polêmica. Uma madrugada, um repórter fotográfico da Folha flagrou o craque Romário descendo de um carro na porta de um hotel, no Rio, com uma moça. Sendo Romário casado à época e não sendo o fotógrafo um detetive particular contratado por sua mulher, a fotografia, como não poderia deixar de ser, provocou celeuma.
Estaria o jornal certo ao alegar o direito à liberdade de expressão para cometer tão evidente invasão da privacidade de uma pessoa, mesmo tendo este indivíduo uma vida, digamos, pública? A meu ver, tal argumento chega a ser um escárnio. Mas também não creio que Romário tivesse razão ao tentar agredir um fotógrafo. Afinal, como diria o cartola Vicente Matheus, "quem está na chuva é para se queimar". Romário vive da fama que construiu nos gramados e, por isso, é, de certa forma, um homem público. Precisa estar preparado para enfrentar a invasão permanente de sua privacidade pela curiosidade do público, que o tornou ídolo. Se quiser privacidade total, que pendure as chuteiras!

Se nenhum dos dois tinha razão, que fazer? O aparente impasse pode ser resolvido com relativa facilidade, mas nunca na arena do direito político, uma vez que a fotografia de Romário com sua presuntiva namorada não tem a mínima relevância social. $\mathrm{E}$, sim, no direito comercial!

A Justiça pode resolver duas questões: se a foto de Romário ajudou a vender jornal — e, se não ajudasse, não teria sido publicada -, o goleador tem direito de reclamar sua parte nos lucros. E, se o prejudicou em sua vida privada, seria o caso de recorrer ao estatuto das perdas e danos, também comercial e sem repercussões políticas de natureza privilegiada.

Nessa discussão, não se pode esquecer a revista semanal Veja, que ainda não aderiu ao primado do marketing e dos serviços sobre a notícia, mas já descobriu as delícias comerciais do fast journalism. Antes de contar o episódio da Veja, gostaria de observar que, nessas cargas de imprensa ligeira, o repórter denuncia, julga e condena a 
personalidade escolhida para o pelourinho. $\mathrm{Na}$ maioria das vezes, age como testemunha, juiz e carrasco.

A imprensa ainda pode dispor, como uma característica dos tempos de "trincheira de combate", de uma espécie de porrete para corrigir as mazelas do regime democrático. A denúncia é vital, sim. Mas é preciso ter algum critério para divulgála, seja ela qual seja. Um episódio que pode ser considerado exemplar para provar isso: a exploração sensacionalista, feita contra educadores de um jardim de infância particular, acusados de abusar sexualmente de seus pequenos clientes. A denúncia original, apresentada por duas mães no $16^{\circ}$ Distrito Policial, em São Paulo, poderia ser o início de uma investigação policial muito séria, mas terminou se transformando em um grotesco espétaculo, protagonizado por um policial, louco para aparecer, e repórteres sem escrúpulos, ensandecidos por notícias para atrair mais a curiosidade popular. A reputação dos educadores foi demolida, a escola, fechada e, no fim das contas, tudo parece não ter passado de exgeros de fantasia infantil.

Não por acaso, o grande crescimento de tiragem da revista Veja - superando a marca de um milhão de exemplares - coincide com o envolvimento de seu noticiário com as denúncias, que terminaram por apear do poder o ex-presidente Collor.

Nunca se esqueçam de que tudo nasceu de uma entrevista do irmão caçula do ex-presidente, Pedro, exatamente à revista semanal de maior circulação no País. Hoje, depois das cargas de imprensa ligeira, ela já é a quarta do mundo, perdendo em circulação apenas para as três gigantes america- nas, Time, Newsweek e U.S. News, mas já batendo a alemã Der Spiegel e vendendo praticamente o dobro da italiana Panorama e mais do que o dobro da francesa L'Express.

A mesma Veja, a cujo sucesso editorial e comercial acabo de me referir, escalou um repórter fotográfico para flagrar em cores um banho de sol da antropóloga Ruth Cardoso, mulher do presidente da República, Fernando Henrique Cardoso. O fotógrafo postou-se em frente ao portão da casa do presidente e esperou que algum veículo entrasse. Entre o abrir e o fechar do portão, a foto foi feita. Terminou sendo publicada.

Evidentemente, a imagem da mulher do presidente de biquíni, mesmo sendo um biquíni discreto, não tem relevância pública. A meu ver, aí mais uma vez não é o caso de se apelar para o velho ideal romântico dos tempos da "fraternidade do combate" para defender a publicação da foto.

Mas, reconheço, também, não haver como resolver o impasse usando estatutos como participação nos lucros obtidos ou perdas e danos. A legislação comercial, para o caso, não basta.

O dilema da publicação, ou não, da foto de dona Ruth de biquíni, colocado pelos organizadores deste seminário na dicotomia entre a discrição e o estereótipo, põe em questão o velho conflito entre o direito à informação e o direito à intimidade, ambos contemplados na Declaração dos Direitos do Homem.

Em princípio, para simplificar, quero crer, o homem público não tem direito à vida privada. Sempre que li, ou ouvi, as queixas do ex-presidente Itamar Franco sobre as invasões que a imprensa promovia de sua vida pessoal, senti-me tentado a lhe escrever para afirmar que, se quisesse vida priva- 
da, não deveria ter sequer concorrido ao cargo de prefeito de Juiz de Fora (MG).

O mesmo conceito vale para o sociólogo Fernando Henrique Cardoso. A vida pública é uma opção. Essa opção inclui, necessariamente, uma espécie de renúncia ao direito humano de privacidade. Mas a renúncia não pode ser estendida à família da, digamos assim, vítima. No caso da foto da mulher do presidente, os companheiros da Veja que me perdoem, se quiserem, vale aquele conceito de Hannah Arendt que o embaixador Celso Lafer reproduziu de forma magistral em seu ensaio sobre o público e o privado no livro A Reconstrução dos Direitos Humanos. O conceito é simples e o reproduzo aqui: "a tutela da intimidade é legítima com base no princípio da exclusividade".

\section{O MERCADO REGULA A MÍDIA}

Aliás, o mesmo episódio da fotografia da mulher do presidente, de biquíni, faz-me lembrar uma frase de um amigo, o engenheiro Luís Guimarães, talentoso profissional do mercado financeiro e pensador nas horas vagas. Para Luís, "não há liberdade possível sem ética".

Então, é preciso ficar bem claro que quando falo da substituição dos privilégios do direito político por uma ética comercial para a atividade da comunicação de massa, em geral, e da imprensa, em particular, não estou aderindo a esta teoria neofascista do controle social dos meios.

Até por causa do entusiasmo com que alguns políticos, socialistas ou neoliberais, aderiram a essa nova forma de censura, chego a acreditar que este tal controle não passa de mais uma forma encontrada pela elite política brasileira para chantagear os meios de comunicação, pondo-os a seu serviço cor- porativo, não ao serviço social, ou seja, de toda a sociedade.

Controle é palavra do dicionário autoritário, cuja letra "c" também abriga censura e chantagem. Afinal, não creio ser a busca obsessiva da verdade contraditória em relação à liberdade de opinião. Para o caso, concordo de novo com Albert Camus, que escreveu, no já lembrado artigo O Jornalismo Crítico: "certamente, o gosto da verdade não impede a tomada de posição".

$\mathrm{Na}$ democracia, a palavra correta, com o mesmo "c" de combate e de crítica, é cidadania. Como costuma advertir o presidente do Congresso Nacional, senador José Sarney, "na prática da democracia, é natural que as instituições se enfraqueçam e a cidadania se fortaleça". É o que ocorre no Brasil, hoje.

Cidadania conquista-se com melhor educação, infelizmente relegada a um plano indigente em nossa não mui serena República. Ainda assim, não se pode omitir a constatação de estar hoje a sociedade brasileira muito mais organizada do que no passado, inclusive se compararmos o momento atual com o breve interregno democrático sob a liberal Constituição de 1946. A crise política do impeachment de Collor, em 1992 e 1993, jogou a sociedade no meio da cena.

Há quem acredite também ter sido aquele o último suspiro do poder da imprensa, pelo menos entendido como o quarto poder. Só se pode constatar isso empiricamente, até porque nunca será possível conseguir provas de uma afirmação do gênero: a perda de poder e prestígio político da imprensa tem sido diretamente proporcional a essa vertiginosa conquista de mercados. Isso se deve, sobretudo, ao desgaste 
da credibilidade, provocado pelo precário senso de responsabilidade social de nossa vite presse.

$\mathrm{Da}$ mesma forma como defendo a mudança dos padrões éticos da atividade da imprensa, admitindo sua natureza empresarial e deixando de viver a ilusão romântica de ser a comunicação apenas uma "fraternidade de combate", aconselho os profissionais da Justiça a prestarem mais atenção nas mudanças que estão ocorrendo em seu redor. Sou absolutamente leigo no assunto e não posso lhes transmitir nenhum dado de minha experiência ou vivência profissional, pois minha única participação na Justiça até hoje foi a de litigante, quase sempre réu.

Como cidadão, e apenas como cidadão, observo que, ao longo dos últimos anos, a Justiça tem encontrado motivos para se acreditar intocável como corporação. Pois, na grande faxina que se pretende fazer no Brasil, até agora ninguém teve a pretensão de mexer com o Poder Judiciário. A República de Alagoas, proclamada por Fernando Collor e sua trupe, propiciou a exposição das vísceras do Executivo. A Quadrilha do Orçamento, chefiada pelo ex-deputado Íbsen Pinheiro, tornou possível a devassa do Legislativo.
É bom que a Justiça desça de seu pedestal e comece a olhar para dentro de seus próprios sótãos soturnos. Até mesmo o fato de ser vista como corporação exige uma reflexão profunda e madura. A sociedade moderna exige mais transparência do Poder Judiciário, por não admitir mais opacidade de nenhum tipo.

Para isso, talvez seja necessária a gestação de algo que possa ser definido grosseiramente como marketing da justiça.

Um bom ponto de partida para essa discussão, na qual, contudo, não me sinto autorizado a entrar, por estado de ignorância absoluta, quase bruta, pode ser a meditação sobre uma frase de Sérgio Adorno, professor da USP. A frase, resultado de uma pesquisa de 20 anos, foi publicada em entrevista nas páginas amarelas da Veja ${ }^{9}$. Ei-la, nua e crua: "o crime evoluiu e a Justiça ficou velha".

Proponho também, neste fim de exposição de argumentos, pedir, ainda uma vez, ajuda à lucidez de Albert Camus, com cujo pensamento tentei iluminar minhas palavras, com uma frase muito inspirada que ele escreveu no artigo Autocrítica, publicado em Combat, em 22 de novembro de 1944: "às vezes, a justiça é uma idéia ou um calor da alma. Saibamos tomá-la no que ela tem de humano, sem transformá-la nesta terrível paixão abstrata, que mutilou tantos homens". 